\title{
BARRIERS TO DISCLOSING CHILD SEXUAL ABUSE (CSA) IN ETHNIC MINORITY \\ COMMUNITIES: A REVIEW OF THE LITERATURE AND IMPLICATIONS FOR PRACTICE IN
}

AUSTRALIA

\section{Pooja Sawrikar and Ilan Katz}

Corresponding author Dr Pooja Sawrikar, School of Human Services and Social Work (HSV), Griffith University (GU), Gold Coast campus, Parklands Drive, Southport, Queensland, 4222, Australia, p.sawrikar@griffith.edu.au

Co-author Professor Ilan Katz, Social Policy Research Centre (SPRC), University of New South Wales (UNSW), Australia, ilan.katz@unsw.edu.au

Highlights • A systematic literature review on child sexual abuse and ethnic minorities was conducted • Barriers to disclosure are a fundamental issue for ethnic minorities, especially need to protect family name • Many cultural barriers to disclosure among ethnic minorities are shared in quality but not quantity with the mainstream • Racism is a unique barrier to disclosure among ethnic minorities; it is not shared with the mainstream • Service worker training may aid culturally appropriate encouragement of disclosure among ethnic minorities

Disclaimer This manuscript has not been published elsewhere, and is not under consideration by any other journal. However, this article reports on the findings from one of six themes explored in a larger study (community awareness, prevention, disclosure, treatment needs, service delivery models, and current national service provision). Thus, content in the Introduction and Method overlaps with content in all prepared articles, but which then report on the findings of one of the explored themes making them each overall different from one another.

Acknowledgments We would like to thank Professor Fiona Arney, Professor Leah Bromfield, Dr Jen Hamer, and Professor Patrick O’Leary for their comments and feedback on an earlier version. We would also like to thank the anonymous reviewers of this article for their comments and feedback, which have been incorporated into the manuscript.

Conflict of interest There is no known conflict of interest. 


\title{
BARRIERS TO DISCLOSING CHILD SEXUAL ABUSE (CSA) IN ETHNIC MINORITY \\ COMMUNITIES: A REVIEW OF THE LITERATURE AND IMPLICATIONS FOR PRACTICE IN
}

AUSTRALIA

\begin{abstract}
Research on child sexual abuse (CSA) among ethnic minority communities in Australia is essentially absent. To begin to address the gap, a systematic literature review was conducted; which necessarily borrowed from overseas to help inform the national context. A wide array of barriers to disclosure were identified, suggesting that this is a fundamental issue for ethnic minorities. The most significant of these barriers appears to be the need to protect family name. This also leads to non-supportive and protective responses from non-offending mothers, however this experience (although more intense) is shared with the Western mainstream. In comparison, fear of stigmatising their whole community is a unique barrier and highlights that racism is a significant and additional burden. The findings suggest that service worker training in Australia is critical for informing professionals of: the importance of family reputation for collectivist groups; the importance of responding supportively and protectively to child victims who have disclosed to them first; the cross-cultural complexities that surround construals of 'child safety'; educating non-offending mothers about the importance of at least believing their child’s disclosure (associated with mediating mental illness among victims, but also culturally appropriate because it acknowledges the protective role of family cohesion in collectivist cultures and the high motivation to avoid social exclusion - the most common reprisal for shaming the family name); exploring acculturation as a possible predictor of disclosure; and the risk of racism being overlooked or minimised. Overall, it is argued that practice informed by a well-developed national research agenda is critical.
\end{abstract}

Keywords Child sexual abuse (CSA), ethnic minorities, disclosure, service delivery, collectivism, racism 


\section{BARRIERS TO DISCLOSING CHILD SEXUAL ABUSE (CSA) IN ETHNIC MINORITY \\ COMMUNITIES: A REVIEW OF THE LITERATURE AND IMPLICATIONS FOR PRACTICE IN}

AUSTRALIA

$1 \quad$ Introduction

\subsection{Background, aims, research questions, and significance}

Little is known about child sexual abuse (CSA) and ethnic minority communities world-wide. As US authors Futa, Hsu, and Hansen (2001) say, "research focusing on sexual abuse in minority populations is minimal” (p. 190). More recently, Tishelman and Geffner (2010) also say, "culture is pertinent to each case of suspected child sexual abuse but only barely (gets) touched on by existing research” (p. 487). Thus, knowledge on whether and how the needs and experiences of ethnic minorities differ from their mainstream counterparts is significantly under-developed. Compared to the US and UK, however, Australia is particularly lagging in its research efforts, as several national researchers note (Bromfield \& Arney, 2008; Burke \& Paxman, 2008; Cashmore, Higgins, Bromfield, \& Scott, 2006; Sawrikar, 2017). Indeed, only one empirical study on CSA across mainstream and ethnic minority groups in Australia was identified in the present literature review study (Taylor \& Norma, 2013). This is seen to be a poor response given that nearly a third of Australia's population (31\%) are first and second generation originating from non-English speaking countries (Australian Bureau of Statistics [ABS], 2012-2013; also see Table 1 for population data on Australia’s largest migrant groups).

However, the Australian context is also particularly unique and sensitive compared to other Western countries. Governments in the past have made what we describe as "grave and horrid mistakes” (Sawrikar, 2017, p. 44) with Indigenous communities that have had irreversible and detrimental repercussions across generations, making them wary to intervene in any non-mainstream group. Between 1910-1970, somewhere between 1 in 10 and 1 in 3 Aboriginal children (Burton, Westen \& Kowalski, 2015) were forcibly removed from their families, who were considered by the government as uncivilised and inferior, to be better parented by white families who were considered to be civilised and superior (Human Rights and Equal Opportunities Commission [HREOC], 1997). These children are referred to as the 'Stolen Generations'. Displacing children and families from their community connections and sense of identity, and negatively judging their parenting and family practices, have led to intergenerational trauma, loss of parenting skills, and over-representation in the child protection system (HREOC, 1997). 
Despite the significance of HREOC’s (1997) Bringing Them Home Report, Indigenous children have continued to be removed from their families at very high rates. In 2007, the 'Northern Territory [NT] intervention' led to the removal of Indigenous children at risk of and experiencing family violence and sexual abuse. The NT Emergency Response (as it is also known) occurred under the Howard government as “an intervention program ... justified through an urgent need to save Indigenous children from widespread abuse and victimisation identified by Anderson and Wild's (2007) Little Children Are Sacred report” (Macoun, 2011, p. 521). The intervention was seen as necessary to protect children (Johns, 2008; Thill, 2009), but it is argued here that it was no more necessary than anywhere else in Australia. This is because sexual abuse occurs in all cultural groups (Finkelhor, 1994; Pereda, Guilera, Forns, \& Gomez-Benito, 2009; Stoltenborgh, van Ijzendoorn, Euser, \& Bakermans-Kranenburg, 2011). Thus, the intervention is seen as racist; it used the need to protect child safety as a justification for intervening in a non-mainstream group only (Johns, 2008; Thill, 2009).

Unfortunately, Australia has not conducted a national prevalence study of CSA (Mathews et al., 2016), so exact numbers are not known. The international literature, however, can aid in being able to make some reasonable guesses. Research from overseas does show that prevalence differs across countries, so by analogy some cultural groups in Australia are likely to have higher prevalence than others, but as already stated the work also shows that it occurs in all groups (Finkelhor, 1994; Pereda et al., 2009; Stoltenborgh et al., 2011). In the only known study on cross-cultural reported prevalence of child maltreatment in the state of New South Wales (NSW) in Australia (Sawrikar, 2011) - unfortunately with only small sample sizes ( $n=20$ per cultural group) - it was found that 4 of 20 (20\%) Chinese, 3 of 20 (15\%) Vietnamese, 1 of 20 (5\%) Lebanese, 4 of 20 (20\%) Pacific Islander (Samoan and Tongan), 8 of 20 (40\%) Aboriginal, and 11 of 20 (55\%) Anglo case files had substantiated reports of sexual abuse.

The relatively low prevalence in the Chinese group is difficult to interpret because the results of international research seems to suggest that prevalence is lower in Chinese populations compared to other groups (Ji, Finkelhor, \& Dunne, 2013; Chen, Dunne, \& Han, 2004). However, the prevalence rates for all four ethnic minority groups explored in this study (Chinese, Vietnamese, Lebanese, and Pacific Islander) are noticeably lower than in Aboriginal and Anglo families, and all case files were randomly selected. These lower rates were attributed at the time to the many barriers to disclosure that ethnic minority groups face, rather than a genuine and substantive higher prevalence among Aboriginal and Anglo families (and one purpose of this article is to identify these barriers as fully as possible). Also notably, the prevalence rate is higher in the Anglo group than in 
the Aboriginal group. The fact that no racialised intervention has occurred for the mainstream in the same way that it has for Aboriginal children - that is, programs targeting only white families and communities due to high prevalence of CSA in them - is seen to be a clear demonstration of the racism and discrimination that non-white families incur, with devastating effects to children, families, and communities. It is important to acknowledge that the needs and experiences of Aboriginal families and communities in the state of NSW are different to those in remote NT. However, all this national context has been provided here to establish the gravity of racism as a barrier to disclosure of CSA among non-mainstream groups, be they Indigenous or ethnic minority (discussed in further detail under 'Results').

By virtue of being non-mainstream in the same way Indigenous Australians are, ethnic minorities in Australia are seen to face to a similar issue: sexual abuse occurs in their communities, but is at risk of being labelled 'a cultural issue' for them. This is a burden that does not exist for the white mainstream (see '3.1.7 Fear of stigmatising their entire community’ for further discussion); abusers and victims from white mainstream families are seen as individual cases and the entire group does not 'pay' for the crime of one or even many. As Huisman, Martinez, and Wilson (2005) more generally say, “for many Whites, for whom race plays little or no role in their everyday lives, it is easier to view people as individuals rather than part of a group ... It is generally beyond their experience to know what it is like to be viewed racially as unmeltable or other” (p. 798). This then creates pressure on minorities for whom “the reality of racism has to be “proven” continually” (Jiwani, 2005, p. 853). In the context of barriers to disclosing CSA, racism among non-white victims/survivors is at risk of being overlooked or minimised.

Despite these complexities and challenges, we see that silence about them is not the appropriate response as it still fails to protect child safety. Instead, we argue that policy makers and practitioners who directly work with issues of child safety must develop a new and efficacious approach to protecting children. Specifically, the approach needs to wholly accept that racist thinking and action is a real threat to non-mainstream families. It also needs to view children from ethnic minority groups as individual victims of criminal abuse rather than cultural victims (also see Sawrikar, 2017 for an in-depth commentary on the experience of racism among ethnic minority CSA victims/survivors). In this way, protection can be offered to all children more equally, while still tailoring that protection to the unique risks that occur for non-mainstream communities.

To this end, this article reports on some of the findings from a larger study on the experiences of victims/survivors of CSA from ethnic minority communities and how best to meet their needs. The larger study 
was a systematic literature review conducted to help address the gap in national knowledge. It explored several themes: (i) current community awareness of CSA in ethnic minority communities and how best to raise it, (ii) barriers to participation in prevention programs among ethnic minority communities and culturally appropriate strategies that could address them, (iii) barriers to disclosure in ethnic minority communities and culturally appropriate strategies that could help encourage it, (iv) the treatment needs of victims/survivors from ethnic minority communities and elements that constitute culturally competent treatment, (v) possible service delivery models for victims/survivors from ethnic minority communities in Australia, and (vi) current service provision to victims/survivors from ethnic minority communities in Australia.

This article only focuses on issues to do with disclosure (theme 3); the results of the other themes are reported elsewhere. Specifically, this article addresses two research questions (RQs): (i) what are the identifiable barriers to disclosure of CSA among ethnic minority communities? and (ii) how can service organisations play a role in helping to encourage disclosure of CSA? Broadly, the results intend to develop capacity in the services sector as well as knowledge about similarities and differences between ethnic minority and mainstream victims. It is thus a significant contribution to the area; the use of a systemic approach to identifying the current relevant literature helps begin address the national gap in knowledge that can in turn inform best practice.

\subsection{Defining 'ethnic minorities'}

To best meet the needs and identify the experiences of sub-groups in the population, it is necessary to define them clearly. Ethnic minority communities are defined here as those who have a migration history and are minorities in at least one of the four main dimensions of ethnicity identified by O’Hagan (1999) - race, language, culture, and religion. Thus, ethnic minority communities are differentiated from their Indigenous and Anglo counterparts. In Australia, there are two distinct Indigenous groups - Aboriginals and Torres Strait Islanders, and white Australians (Anglo Saxon and Celtic) form its mainstream. Ethnic minorities usually come from non-English speaking countries of origin, which also tend to be high on collectivism (see ' 1.3 Theoretical framework' for more information). The term includes refugees and asylum seekers, but these groups have needs and experiences over and above those of other ethnic minorities (Allimant \& Ostapiej-Piatkowski, 2011), so literature on the broader category should not be seen as sufficient for this niche group. In Australia, a synonymous term is used in the research, practice, and policy discourse - 'culturally and linguistically diverse' (CALD). This term has not been used here because the term 'ethnic minorities' draws attention to all four dimensions of ethnicity, not just culture and language (Sawrikar \& Katz, 2009). 'Non-mainstream’ groups refer 
to Indigenous and ethnic minority communities. They have in common lower social, economic, and political power compared to the white mainstream, but also differ from one another in their needs and experiences and in the definitive characteristic of being First People or having a migration history.

As can be seen from Table 1, most overseas-born people in Australia originate from countries such as the UK (North-West Europe), and many also come from New Zealand (Oceania and Antarctica). However, of those from non-English speaking countries, most are from Asia including China and India, and Southern and Eastern Europe including Italy and Greece.

Table 1: Overseas country of birth by region (ABS, 2016)

\begin{tabular}{|c|c|c|}
\hline Region of birth & Persons & $\begin{array}{l}\text { Proportion of overseas-born } \\
\text { population (\%) }\end{array}$ \\
\hline North-West Europe & $1,431,169$ & 23.2 \\
\hline South-East Asia & 872,891 & 14.2 \\
\hline North-East Asia & 789,436 & 12.8 \\
\hline Southern and Central Asia & 782,903 & 12.7 \\
\hline Southern and Eastern Europe & 657,698 & 10.7 \\
\hline Oceania and Antarctica(a) & 657,696 & 10.7 \\
\hline Sub-Saharan Africa & 317,182 & 5.1 \\
\hline Middle East & 303,089 & 4.9 \\
\hline Northern America & 129,704 & 2.1 \\
\hline South America & 114,599 & 1.9 \\
\hline Other Americas $^{\mathrm{a}}$ & 21,751 & 0.4 \\
\hline North Africa & 70,994 & 1.2 \\
\hline Total $^{\mathrm{b}}$ & $6,163,667$ & 100 \\
\hline
\end{tabular}

Source: Census of Population and Housing, 2016; a - Other Americas includes Central America, Caribbean and

Americas, nfd; b - Total includes Inadequately described, At sea, and North Africa and the Middle East, nfd.

\subsection{Theoretical framework}

'Collectivism' is a cultural stance that sees the basic unit of society to be the family, and it is differentiated from ‘individualism’ which sees the individual to be the basic unit of society (Hofstede, 1980). More specifically, 
collective cultures value social order, harmony, support and roles; the family provides security in exchange for loyalty and obedience; inequality (usually based on age and gender) is seen as appropriate and acceptable; and members tend to be more homogenous as deviations from the norm are not tolerated as greatly (Bond, 2002; Triandis, 1990). In contrast, individualistic cultures value independence, autonomy, initiative and uniqueness; emphasise that individuals have the right and responsibility to look after themselves; stress horizontal relationships based on equality; and tolerate deviations from the norm to a greater extent (Bond, 2002; Triandis, 1990).

According to the seminal researcher Hofstede (2001), the US, Australia, UK, Canada, and New Zealand, rank highest on individualism. Western European countries rank next highest, and the remaining parts of the world (such as East Europe, Asia, South America, Middle East, and Sub-Saharan African) rank more highly on collectivism. The implication is that many ethnic minorities in Western countries like Australia originate from non-Western countries high on collectivism (see Table 2 for more information).

Table 2: Individualism (IDV) scores by country ${ }^{1}$

\begin{tabular}{|c|c|c|c|c|c|c|c|}
\hline Country & IDV & Country & IDV & Country & IDV & Country & IDV \\
\hline Unites States & 91 & Czech Republic & 58 & United Arab Emirates & 38 & Sierra Leone & 20 \\
\hline Australia & 90 & Austria & 55 & Turkey & 37 & Singapore & 20 \\
\hline United Kingdom & 89 & Hungary & 55 & Uruguay & 36 & Thailand & 20 \\
\hline Netherlands & 80 & Israel & 54 & Greece & 35 & El Salvador & 19 \\
\hline New Zealand & 79 & Spain & 51 & Philippines & 32 & South Korea & 18 \\
\hline Italy & 76 & India & 48 & Mexico & 30 & Taiwan & 58 \\
\hline Belgium & 75 & Argentina & 46 & Ethiopia & 27 & Peru & 16 \\
\hline Denmark & 74 & Japan & 46 & Kenya & 27 & Costa Rica & 15 \\
\hline France & 71 & Iran & 41 & Portugal & 27 & Indonesia & 14 \\
\hline Sweden & 71 & Jamaica & 39 & Tanzania & 27 & Pakistan & 14 \\
\hline Ireland & 70 & Brazil & 38 & Zambia & 27 & Colombia & 13 \\
\hline Norway & 69 & Egypt & 38 & Malaysia & 26 & Venezuela & 12 \\
\hline Switzerland & 68 & Iraq & 38 & Hong Kong & 25 & Panama & 11 \\
\hline
\end{tabular}

\footnotetext{
${ }^{1}$ http://www.clearlycultural.com/geert-hofstede-cultural-dimensions/individualism/
} 


\begin{tabular}{|lc|lc|lc|lc|}
\hline Germany & 67 & Kuwait & 38 & Chile & 23 & Ecuador & 8 \\
\hline South Africa & 65 & Lebanon & 38 & China & 20 & Guatemala & 6 \\
& & & & & & \\
\hline
\end{tabular}

It is also known from the extensive literature on acculturation that cultural norms, values, beliefs, and traditions from the country of origin do not simply disappear into a 'melting pot' in the new country after arrival. The seminal work of Berry (1980) highlights that migrants continuously manage two conflicting needs - the need to preserve the culture of origin and the need to adapt to the new culture. Moreover, this balance is affected by a number of variables, some of which are dynamic and responsive to changing social cues (Sawrikar \& Katz, 2010; Sawrikar \& Katz, 2009; Sawrikar \& Hunt, 2005). For example, the conflict is affected by whether the person speaks or understands their native language (where language strongly predicts ethnic identity), their generational status (where those born overseas are less likely to be integrated), their developmental age (where need for group belonging and acceptance may be higher among adolescents), whether they are visibly different to the mainstream (such as through skin colour or religious attire), how much they experience racism and discrimination (if at all), where they reside (with different local areas varying in acceptance of multicultural diversity), and the impact of political discourse on the national and global stages (such as the vilification of Muslims, or refugees and asylum seekers derogatorily described as 'boat people'). Thus, cultural norms and values from the country of origin (such as collectivism) are pervasive in the daily life and social structures of ethnic minority communities, even among well-established migrant groups and across generations.

The theoretical framework of individualism/collectivism has utility in the context of CSA because collectivist cultures place greater value for family and community over the needs of individuals. As such, the needs of victims may be de-prioritised to the needs of the family, most especially the need to protect the family's reputation or 'face'. It is also relevant because collectivist cultures overtly accept gender inequalities - the father is seen to be the head of the family, has most of the power within the family, and in turn is most associated with the family's 'face' or reputation. Allegations of CSA against fathers or other senior males are therefore perceived as accusations against the whole family, so in order to save 'face' it is often the accuser and/or victim that is excluded by the family rather than the alleged abuser (discussed in detail under 'Results').

Importantly, themes of family, reputation, patriarchy, silence, and exclusion also occur in individualistic groups because individualism and collectivism really occur on a continuum, but groups tend to be heuristically categorised as one or the other. Thus, the use of the theoretical framework is not to minimise the importance of 
these themes in 'individualistic' cultures, but to highlight their centrality among 'collectivist' ones. This is necessary when attempting to identify how best to protect children in these communities; it provides a culturally relevant 'lens' for making sense of their needs and experiences. It therefore aligns with social constructionism (that perceived reality is constructed by personally meaningful and relevant variables), cultural relativism (that not all cultures can or should be compared, as if they all occur along comparable dimensions), and emic methodologies (that ‘insider’ perspectives matter; both authors are ethnic minorities) (Sawrikar, 2017).

Although the framework is seen to be useful, it is still important to point out that 'individualism' and ‘collectivism' are just generalised stereotypes, so should not be definitively relied on. They need to be used with vigilance, ensuring that the beliefs comprising the stereotypes are accurate, do not perpetuate harm or disadvantage to groups, and are questioned when applied to individual situations (Sawrikar, 2017). This is particularly critical for clinical practice because stereotyped assumptions about culture can result in inappropriate and even harmful outcomes (Owusu-Bempah \& Howitt, 2000). Thus, macro-level conceptualisations of culture should be combined with more nuanced and detailed constructions of culture that occur within each minority group to better engage with victims from them. That is, the theoretical framework of individualism/collectivism is seen as necessary but not sufficient for understanding CSA among ethnic minority communities.

\section{$2 \quad$ Method}

\subsection{Databases, keywords/search terms, and inclusion/exclusion criteria}

The methodology for obtaining the relevant literature was informed by the Preferred Reporting Items for Systematic Reviews and Meta-Analyses (PRISMA) process. The PRISMA flow diagram (Moher, Liberati, Tetzlaff, Altman, \& the PRISMA Group, 2009) is in Figure 1.

Literature was first sourced from relevant databases - Australian Public Affairs Full-Text, Health and Society Database, Informit Family and Society Collection, Informit Health Collection, Informit Humanities and Social Sciences Collection, Multicultural Australia and Immigration Studies, ProQuest Family Health, PsycINFO, Scopus, Social Services Abstracts, and Sociological Abstracts.

Then, a series of search terms related to the two keywords - 'child sexual abuse' and 'ethnic minorities' - were combined. Search terms related to the first keyword included: sexual abuse, sexual harassment, sexual exploitation, molestation, rape, indecent assault, sexual violence, and gender violence. Search terms related to 
the second keyword included: culture (cultur*), race (rac*), culturally and linguistically diverse (CALD), nonEnglish speaking background (NESB), ethnic minority/ies (ethni*), migrant, immigrant, refugee, asylum seeker, of color/colour, and community.

\section{Figure 1: PRISMA flow diagram}
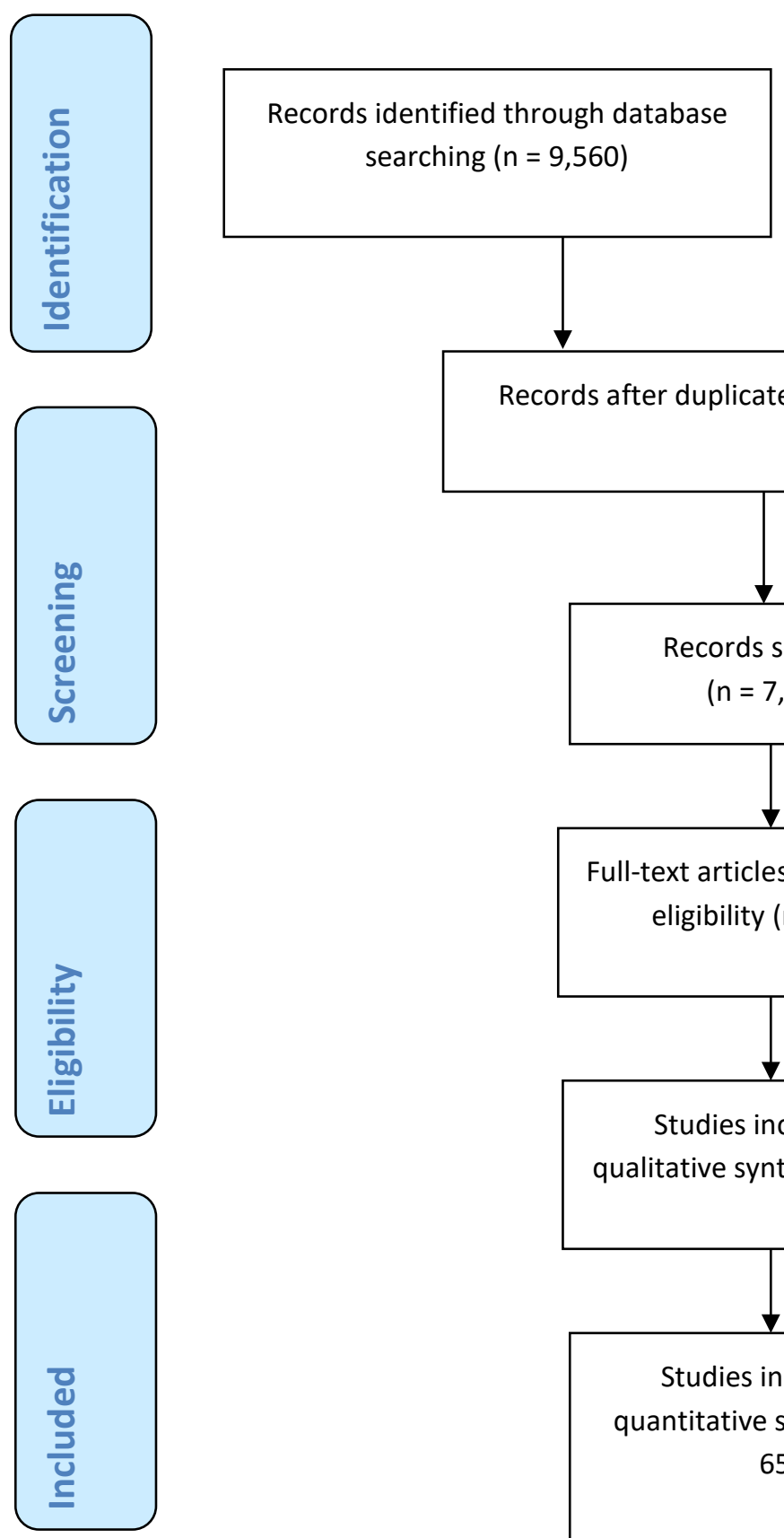

Additional records identified through other sources $(n=0)$

Records after duplicates removed $(n=7,363)$

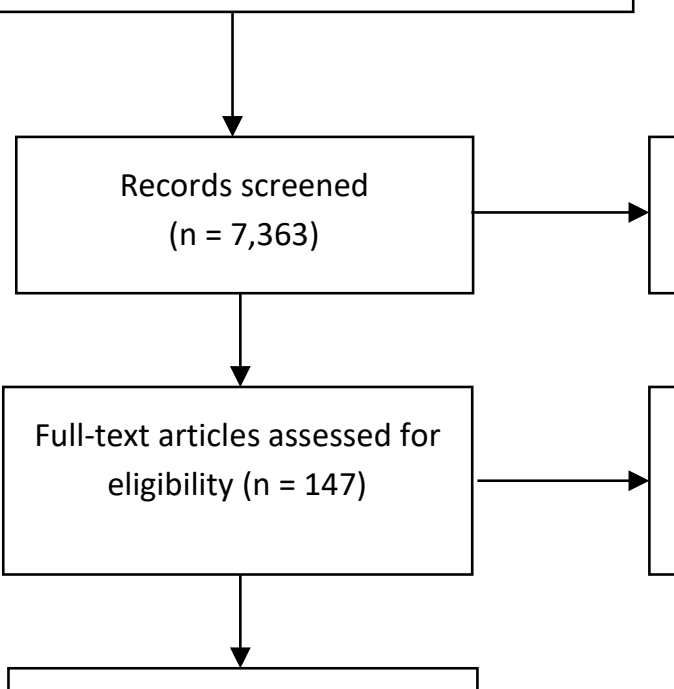

Records excluded $(n=7,216)$

Full-text articles excluded, with reasons $(n=12)$

Studies included in qualitative synthesis $(n=42)$

Studies included in quantitative synthesis $(\mathrm{n}=$ 65) 
Searches were limited to 2000-2016 to ensure only recent literature was included. Where available, searches were also limited to full-text, English, and peer-reviewed only. These criteria led to 9,560 results. Duplicates were then removed $(n=2,197)$, reducing the number of records to 7,363 . They were then screened for their relevance to the six themes of the larger review based on their title, keywords, and abstract. Most of the literature was excluded at this stage. Although the Boolean logic of 'AND' had been used to combine search terms related to the two keywords, the searches mostly did not yield literature specifically related to sexual abuse experienced in childhood by someone from an ethnic minority background (i.e. ethnic minorities in Western countries or about non-Western countries). Most commonly, articles were excluded because they related to sex offenders and/or recidivism, sexual risk behaviour but not sexual abuse, elder (sexual) abuse, military culture, and substance abuse, men who have sex with men, and women who have sex with women but not sexual abuse. In total, 6,715 records were deleted at this stage. Of the 648 remaining articles, the full text of 20 was not available, leaving 628 records. Of these, 421 related to sexual violence, gender violence, domestic violence (DV), intimate partner violence (IPV), sexual exploitation, and sexual harassment among adults rather than children or survivors of CSA in ethnic minority communities, or were about violence that involved children but not CSA (such as witnessing DV); these too were excluded.

Literature was then excluded if it only pertained to Native Americans $(n=6)$ and African Americans $(n=25)$ to address a priori issues to do with the transferability of findings from Indigenous groups in other Western countries and/or minority groups not represented in Australia. Although there are some families from South America represented in Australia (see Table 1), literature only pertaining to Latina/Hispanic Americans $(\mathrm{n}=29)$ was also excluded on the grounds that they form a large and significant minority group in the US and so their needs and experiences could be quite specific to that context. Indeed, in a literature review on CSA in minority communities in the US, Kenny and McEachern (2000) found that "many studies utilised Asians in their homelands and Asian-Americans, while research examining Hispanics utilised only Hispanic immigrants to the United States” (p. 906). Note: studies that explored and compared all three (and only these three) groups Native, African, and Latina/Hispanic Americans - were also excluded and were counted under 'Latina/Hispanic American’ in this study. On the other hand, literature that addressed groups in addition to Native, African, and Latina/Hispanic Americans - for example, Asian-Americans (because Asian-origin migrants are highly represented in Australia, see Table 1) - were included in this review, so the former groups have not been wholly disregarded. This is particularly helpful for ensuring that racial and other barriers common among all ethnic minorities are represented to some extent in the review. 
Applying the above exclusion criteria left a total of 147 records eligible for full review. Once the full text of these had been read, however, 12 were identified as not being directly relevant to the larger systematic literature review. This refined and reduced the final number of records to be in scope of the review to 135 . Of these, 42 primarily used qualitative methodologies (such as in-depth interviews, focus groups, and case studies), 65 primarily used quantitative methodologies (such as surveys, case file reviews, and meta-analyses), eight used a mixed-methods approach (counted under the 'Quantitative’ records), and 28 used secondary analyses (such as literature reviews and commentaries). As the secondary analysis records did not use either qualitative or quantitative methodologies, they do not appear in the flowchart. Only articles relevant to the two research questions (RQs) of this article have been cited here, and Appendix A contains a summary of each cited study’s location, the ethnic groups investigated, their method, and whether it could be deemed rigorous. The broader literature on ‘child maltreatment and ethnic minority communities' as well as 'family violence and ethnic minority communities', which have been explored by the authors in previous research projects, were also drawn upon where relevant.

\subsection{Strengths and weaknesses}

The approach for obtaining the literature was systematic, comprehensive, and exhaustive. Emergent themes from the literature were also exhausted, and have been comprehensively reported under 'Results' in the form of a narrative review merging description and analysis (while also keeping a need for brevity in mind). Still, some weaknesses of the methodology and review need to be acknowledged.

The first is that the body of literature on CSA and ethnic minorities is small, as already stated. Moreover, not all of it is based on empirically rigorous methodologies (see Appendix A). This limits being able to offer evidencebased principles of best practice for encouraging disclosure (one key purpose of this paper), with only suggestions being able to be offered. Still, literature on mainstream samples in Western contexts cannot and should not be used to make sense of the needs and experiences of ethnic minorities, which several authors note (Baker, Gleason, Naai, Mitchell, \& Trecker, 2013; Chen \& Chen, 2005; Chien, 2013; Elbedour, Abu-Bader, Onwuegbuzie, Abu-Rabia, \& El-Aassam, 2006; Gilligan \& Akhtar, 2005; Mildred \& Plummer, 2009; Reavey, Ahmed, \& Majumdar, 2006; Sil \& Soo, 2008; Wang \& Heppner, 2011; Usta \& Farver, 2010). As Capri (2013) says of the South African context but with transferability to all ethnic minorities, "North American, British, and European assumptions around child sexual abuse offer an inadequate framework for understanding such abuse in South Africa. Without reflecting critically on these assumptions, we risk obscuring, silencing and 
recolonising children's experiences. We constrain knowledge, restrict the identities of South African sexually abused children, and limit spaces for healing” (p. 34).

Another limitation is that the review has grouped several different races, cultures, languages, and religions together, falsely homogenising each of their needs. It can be somewhat justified on the grounds that minorities share some experiences such as language barriers, racism and discrimination, and a collectivist background, however such ‘ethnic lumping’ (Fontes, 1993) does fail to pay attention to more nuanced detail about cultural norms, values, beliefs, and traditions regarding CSA in specific groups. We see that these limitations must at least be acknowledged, if they cannot be addressed, as part of ethical conduct in research. Indeed, limiting research to English-only articles is also problematic because it excludes voices from various countries of origin; multilingual scholars can and should address this in future research.

Another issue is that much of the literature about ethnic minorities is from other Western countries such as the US, UK, Canada, and New Zealand. This poses issues for the transferability of findings to Australia. This was somewhat addressed by excluding literature that related solely to groups not represented in Australia (such as Native and African Americans), however caution still needs to be exercised. Reasonable comparisons can be made but other countries do have a different 'ethnic profile’ to Australia, with different specific groups and sizes comprising their migrant community, as well as reasons for their migration to these countries, all of which affect their socio-cultural and political standing (Sawrikar \& Katz, 2008).

There is also the issue that themes identified in literature from non-Western countries may become limited or even irrelevant to migrants from those countries because the experience of being an ethnic minority in a Western country is so different to their experiences in their country of origin. Moreover, literature from non-Western countries is not equally represented; most is about East Asians, South Asians, sub-Saharan and South Africans, Arabs, and Jews, so the experiences of other groups are even less well documented. In order, Australia's largest migrant groups from non-English speaking countries of origin are from China, India, Philippines, Vietnam, Italy, South Africa, and Malaysia (ABS, 2016). There has also been a recent increase in the number of people from Africa, commonly entering on humanitarian visas (ABS, 2012). Thus, current non-Western literature is helpful to some extent but not sufficient to cover the breadth of applicability required. It also relies on the reasonable assumption that since norms, values, beliefs, and traditions do not simply disappear after migration, literature from countries of origin are useful to include (while acknowledging that acculturation is dynamic and therefore individual variation in the extent to which these things transfer after migration also occur). 
Notwithstanding these methodological limitations, this review has included articles from diverse backgrounds which is a global approach consistent with and required for issues that address multiculturalism. Overall, the results indicate that there are a wide array of reasons why a victim/survivor of CSA from an ethnic minority background would not disclose the abuse, strongly suggesting that issues surrounding disclosure are fundamental in this group. These barriers have been comprehensively reported below (RQ 1), along with clearly articulated implications for practice in terms of how service organisations could help address them (RQ 2).

\section{$3 \quad$ Results}

\subsection{RQ 1: What are the identifiable barriers to disclosure of CSA among ethnic minority communities?}

Table 3 summarises the barriers to disclosure of CSA among ethnic minorities identified in the reviewed literature. Overall, the findings indicate that most barriers are cultural in nature, and many are shared with the mainstream so are not culturally specific to ethnic minorities. As this review aimed to thematically scope the full array of barriers relevant to ethnic minorities, it is not possible to prioritise them in order of importance with certainty. The number of barriers experienced by an individual ethnic minority victim/survivor, how important they are each perceived by them, and ways they interact for them, would vary and need to be ascertained at a case-by-case level. Still, some notion of the importance of each of these identified barriers is given by the number of authors who discuss them. Each barrier is described in more detail below.

Table 3: Summary of all barriers to disclosure of CSA among ethnic minorities

\begin{tabular}{|l|c|c|}
\hline Barrier to disclosure & Cultural & Shared with mainstream \\
\hline Universal barriers (such as embarrassment, & No & Yes \\
\hline Preserving the family name & Yes & Yes (but more intensely) \\
\hline Lower social power of children & Yes & Yes (but more intensely) \\
\hline Social norms regarding emotional & Yes & Yes \\
suppression & & \\
\hline
\end{tabular}




\begin{tabular}{|l|c|c|}
\hline Fatalistic and/or religious beliefs & Yes & $\begin{array}{c}\text { Yes (insufficient literature on } \\
\text { whether more intensely) }\end{array}$ \\
\hline Fear of reprisal - social exclusion & Yes & Yes (but more intensely) \\
\hline Fear of reprisal - honour killings & Yes (when collectivist value & No (however insufficient \\
for family name cited) & literature in mainstream samples) \\
\hline killings) & No (when collectivist value & Yes \\
\hline Fear of stigmatising their entire community & No (racial not cultural & No \\
\hline Fear of non-supportive and protective & barrier) & Yes (but more intensely) \\
responses to disclosure especially from \\
mothers
\end{tabular}

\subsubsection{Universal (non-cultural) barriers}

Key barriers to disclosure that victims/survivors from ethnic minority communities face are those they share with other victims/survivors. These include embarrassment, guilt, fear of not being believed, lack of awareness regarding rights, lack of willingness to confront the criminal justice system, and difficulty understanding the criminal justice system (AlMadani, Bamousa, Alsaif, Kharoshah, \& Alsowayigh, 2012; Sulimani-Aidan \& Benbenishty, 2013). These work to create "intense shame leading to secrecy” (Kenny \& McEachern, 2000, p. 907), and therefore significant under-reporting (Yoshihama \& Horrocks, 2010; Shalhoub-Kevorkian, 2005).

Kenny and McEachern (2000) say that as many as $80 \%$ of sexual abuse cases may not be reported. Collings, Giffiths, and Kumalo (2005) also state that "disclosure tends to be the exception rather than the norm, with estimates of nondisclosure varying from 33-92\% for girls and from $42-100 \%$ for boys” (cited in Lam, 2014, p. 769). Thus, universal barriers already play a central role in understanding the delays, or even failure, in disclosing abuse among victims/survivors from ethnic minority communities.

\subsubsection{Preserving the family name}


For minority groups, however, fear of shaming or dishonouring the family name also appears to be another significant barrier because it directly threatens definitive collectivist values for the family over the needs of individuals. The literature was rife with examples of collectivist values for the family name as the reason for silence about CSA. It was noted in South Asian communities (Gilligan \& Akhtar, 2005; Singh, 2009), East Asian communities (Back, Jackson, Fitzgerald, Shaffer, Salstrom, \& Osman, 2003; Chan, Lam, \& Shae, 2011; Chen et al., 2004; Foynes, Platt, Hall, \& Freyd, 2014; Futa et al., 2001; Lesmana, Suryani, \& Tiliopoulos, 2015; Li, Ahmed, \& Zabin, 2012; Lin, Li, Fang, \& Lin, 2011; Ma \& Li, 2014; Sil \& Soo, 2008; Ullman \& Filipas, 2005), Jewish (Neustein \& Lesher, 2008; Sulimani-Aidan \& Benbenishty, 2013), Saudi Arabian and Palestinian Arab communities (AlMadani et al., 2012; Haj-Yahia \& Tamish, 2001), in Zimbabwe (Kaseke, 2010), and in Papua New Guinea (Lewis, 2012).

As an example to help contextualise the issue, Sil and Soo (2008) say, "in Korea, a father who perpetrates father-daughter incest faces fewer consequences, and a victimised daughter suffers greater hardships, compared with those in Western countries (because) the family may overlook the sufferings of the victim to preserve family dignity and honour” (p. 79-80). Other examples were also offered in the literature. Lewis (2012) reports that in Papua New Guinea (PNG), “disclosure of CSA is seen as talking in a "bad” way about relatives. (This) maintains secrecy and isolation and prevents healing for victims” (p. 291). In Israel, Ajzenstadt and Cavaglion (2005) say, "the dominant ideology is that the family is a safe place, childhood is at the core of social life, and high value is placed on loyalty to parents. (These) all serve to make dealing with child abuse within the family akin to violating a taboo” (p. 264). Finally, “a woman (in many groups) who has lost her virginity prior to marriage is viewed as a disgrace to herself and her family. Thus (she) may choose not to disclose the abuse” (Kenny \& McEachern, 2000, p. 910).

Importantly, Taylor and Norma (2013) - in the only empirical study found in Australia on the experiences of CSA across mainstream and ethnic minority groups - found that "fear of bringing shame to the family" (p. 120) also affected disclosure rates and delays among Anglo Australian victims. It is a critical reminder that 'individualism' and 'collectivism' really occur on a continuum, and the context of CSA seems to reveal the collectivist or familial elements that exist in 'individualistic' societies. Thus, fear of shaming the family name is relevant to ethnic minorities in quantity/intensity, rather than quality/nature; it is a cultural barrier, but not a 'culturally specific' one because social and familial consequences can outweigh the benefits of disclosure to individuals in all groups. Indeed, Fontes (1997) says, “whites are often considered 'culture free’ or 'without 
ethnicity’ in research studies because they are the racially dominant group” (p. 9). It is therefore important to remember that cultural barriers, and in particular those that relate to the family name, also exist for the Anglo mainstream.

\subsubsection{Overt lower social power of children}

Another cultural barrier to disclosure may be the lower social power of children. As an example, Fontes (1993) says, "the Hispanic cultural norm that children will always obey adults may lead children to comply with adults' sexual advances and maintain silence if any adult has forbidden disclosure” (cited in Kenny \& McEachern, 2000, p. 910-911). As another example, Chan et al. (2011) say, "filial piety of the Confucius teachings (in China) ... stresses authority over children and expects unquestioning obedience from them” (p. 163). Thus, “the subordinate position of the child (in Chinese culture) may (also) make the adult less likely to believe such reports” (Choi, Choo, Choi, \& Woo, 2015, p. 81).

It is important to point out that the needs of child survivors of sexual abuse who disclose as adults are very different to those who disclose as children and so go through the child protection system (Fanslow, Robinson, Crengle, \& Perese, 2007; Fontes, 2005). That is, the consequences of bringing (especially an intrafamilial) perpetrator to the attention of the child protection system has a huge bearing on a child, especially when they are from a collectivist culture with overtly less power than adults.

Critically, Karthiga and Ravikumar (2014) point out that "childhood is a lengthy period of apprenticeship and secondary status in most human societies” (p. 728). Thus, lower social power of children occurs in all cultural groups. It is only a 'culturally specific' barrier to disclosure in ethnic minority communities in that it is comparatively more overt in collectivist cultures, where differentially ascribed power to elders is seen as normal, acceptable, and of value (see also ‘1.3 Theoretical framework’).

\subsubsection{Social norms regarding emotional suppression}

Social norms about the expression of emotions may also act as a barrier to disclosure. For example, Futa et al. (2001) argue that Asian cultures tend to espouse 'middle position virtue', which emphasises harmony, discourages conflict, and causes inconspicuousness. Foynes et al. (2014) similarly say that "disclosure could be seen as counter to an ideal of emotional suppression, which is valued (in Chinese culture) as an indication of strength and self-control, particularly when it is used to enhance relationships” (p. 135). 
Importantly, norms valuing emotional suppression are not exclusive to ethnic minority communities. Our previous related work notes fear of not being seen as emotionally self-reliant (Sawrikar, 2008) in Western/individualistic countries. Stigma for seeking professional help for mental illness (Corrigan, 2004) is also reported in these samples. Thus, social norms regarding emotional suppression are not seen as 'culturally specific' to ethnic minority communities. Norms that ask for emotional suppression occur in all cultural groups, but as has been argued elsewhere, are driven primarily by a value to preserve family harmony in collectivist cultures, and primarily by a value for self-sufficiency in individualistic cultures (Sawrikar, 2008).

\subsubsection{Fatalistic and/or religious beliefs}

Fatalistic and/or religious beliefs about the utility of disclosing abuse may also act as a barrier. Again, such beliefs are cultural but not exclusive to ethnic minority communities. It is also not known how such beliefs interact with ethnicity. For example, Catholicism will be practiced differently between Filipinos, Hispanics, and Anglos, and more research to tease this out is required. Some brief examples from the reviewed literature of this barrier are reported below.

Futa et al. (2001) say, “Asian-Americans’ sense of stoicism, and acceptance of their consequences, may prevent them from disclosing the pain of child abuse” (cited in Kenny \& McEachern, 2000, p. 910-911). Haboush and Alyan (2013) say, "the degree to which beliefs in fate and divine will may discourage (Muslim) Arab Americans from assuming a more personal locus of control and attempt to alter the course of events through reporting child sexual abuse is unknown” (p. 511). Fontes and Plummer (2010) write, “Catholic women and girls may be expected to suffer in silence, as a cross they simply have to bear” (p. 502). Finally, Luo (2000) says, “(in) Buddhism, any negative life event, such as rape, is caused by the individual's karma from previous lives (so) revenge (e.g. punishment of the rapist through prosecution) should not be sought to avoid a karmic vicious cycle” (cited in Fontes \& Plummer, 2010, p. 503).

\subsubsection{Fear of reprisal}

The literature suggests that victims/survivors of CSA from ethnic minority communities can have severe cause for fear of reprisal, acting as another significant barrier to disclosure. Most commonly, reprisal occurs in the form of social exclusion, but sometimes it can result in death. Both these risks are related to the collectivist value for family, and as such are seen to represent cultural barriers. As Allimant and Ostapiej-Piatkowski (2011) 
put it, immigrant women can have "legitimate fears of being disbelieved or blamed, and possible exclusion or persecution from their community” (p. 8).

\subsubsection{Social exclusion}

Among collectivist groups, limited marriage prospects for the abused child and all their siblings are a common example of social exclusion (see '3.1.8.2 Fear of non-supportive and protective responses to disclosure especially from mothers’ for more information on social exclusion); “look at my daughter! How can we ever get her married? She carries a permanent stain on her character", said the father of an abused South Asian child in one case study in the UK (Laungani, 2003, p. 390). Similarly, in Zimbabwe, “a girl who has had sexual intercourse, whether consensual or not, has less chance of contracting a marriage that will contribute lobola (bride price) to the family. Thus, the sexual abuse of a girl has grave economic consequences for the family” (Armstrong, 1998, p. 144, cited in Lalor, 2004, p. 447).

Boakye (2009) explains that when a guardian (in Ghana) claims, "this shame will follow the daughter all her life and she may never get a suitor” (p. 960), that in this context, "shame is 'protecting' the 'broader' interest of the child, but also protecting the broader ‘interest of the family’ (because) every individual has a stake in and responsibility to protect that family name and reputation, including the child ... Consequently, the reputation and interest of the family is put above that of the abused child (and little thought is given to the) immediate and long-term effect of the abuse on the child (or the risk of repeated abuse)” (p. 960-961).

\subsubsection{Honour killings}

In the most extreme circumstances, a victim/survivor (especially female) may not disclose the abuse due to fears for her life. This was noted in Indian (Singh, 2009) and Chinese (Wang \& Heppner, 2011) samples, but more commonly in Arab groups. As an example, Haj-Yahia and Tamish (2001) say, “an (Arab) woman’s purity and honour reflect the ability of her father, brothers, and other men in her extended family to protect her. Therefore, [they] are under tremendous and continuous pressure to try to control women's behaviour. Irreparable damage (occurs if) sexual misconduct becomes public knowledge. Consequently, sexually abused girls and women are not only blamed for their situation but also feel their lives are in real, serious danger” (p. 1305).

Shalhoub-Kevorkian (2000) also says, "Palestinian-Arab society is administrated by the power and interests of the collective rather than of the individual. Early marriage and femicide (viewed culturally as 'killing to preserve family honour') are only some examples to show that female sexuality can be used as a means to 
control or even abuse women. 'Obedience orders', (that) force wives who leave their husbands to return to them, reflect the social perception that women should be controlled and governed by their male family members. This puts [them] in a catch-22. Despite their need for help and support, they also need to silence knowledge of [the abuse] for fear of wreaking on themselves harsh reactions and punishments by society” (p. 622-623). Children’s fear of disclosure is further “affirmed and increased by helpers' fear that girls could be ostracised or killed for disclosing” (Shalhoub-Kevorkian, 2000, cited in Sulimani-Aidan \& Benbenishty, 2013, p. 33).

\subsubsection{Death threats (not honour killings)}

Importantly, fear of the perpetrator also occurs in Anglo families who may threaten to kill the victim, their pet (Taylor \& Norma, 2013), or other family members if they disclose the abuse. Thus, fear for physical safety can be from both non-protective family members and perpetrators, and is not a barrier exclusive to ethnic minority communities. It is, however, cultural for minority communities when the collectivist value for family name plays a role.

\subsubsection{Fear of stigmatising their entire community}

Collectivist pressure to preserve the family name and its honour "is a particularly serious and pernicious barrier" (Taylor \& Norma, 2013, p. 115) among ethnic minority communities, however the findings so far demonstrate that it is not exclusive to them. There are also several other cultural barriers that are not exclusive to minority communities (as stated above). In comparison to these, there is one barrier to disclosure that is unique to this group: fear of stigmatising their entire community. As Barker-Collo, Read, and Cowie (2012) put it, "if one is a member of a minority or disenfranchised cultural group, then one may have the added burden of the abuse potentially being perceived as a 'cultural’ issue” (p. 438).

These authors go on to say that "to avoid risking their cultural group represented as abusive, groups may reject the occurrence of abuse, the individual who reports abuse, or both” (Barker-Collo et al., 2012, p. 438-439). Menjivar and Salcido (2002) similarly say, from the family violence literature, “ethnic minorities may trivialise, ignore, and resist acknowledging domestic violence in their community for fear of stigmatisation” (cited in Salter, 2014, p. 106).

Using her own experiences as an African American woman surviving incest, Wilson (1993) writes that "when a white child is sexually abused, they think they are bad and dirty. When a black child is abused, she thinks she is bad, dirty, and an affront to the race. She thinks, too of the message it will send to white society if she tells" 
(cited in Jackson, 2010, p. 7). Thus, “they may be seen as 'race traitors' if they disclose” (Wilson, 1994, cited in Fontes \& Plummer, 2010, p. 500). Bernard (2002) also talks of the impact of societal racism in the UK on black children's public voicing of abusive events; “finding their voice creates a tension for children, because they are wracked with conflict, guilt, and ambivalence about loyalty and betrayal. The fear of undermining their family in a racist society exert(s) a powerful influence on them to remain silent” (p. 242). As Fontes and Plummer (2010) put it, “a child's refusal to disclose may be an unfortunate side effect of a highly adaptive trait - to protect one’s community from hostile outsiders” (p. 501).

More recently, after Sheik Hilaly’s sexist sermon in Sydney in 2006 where he stated that "when it comes to adultery [his words, and in relation to a rape case being heard at the time], it's 90 per cent the woman's responsibility” (Henderson, 2007, p. 9) - Henderson (2007) importantly pointed out that “in addition to the further silencing of female Muslim victims/survivors from seeking help, it also leaves moderate Muslim men looking as if they are all born rapists” (p. 10). Salter (2014) also warns against the use of Islamophobic discourse in Australia, arguing that "linkages between masculine status and gendered violence that transcend ethnic or cultural boundaries have often been overlooked in controversies over 'honour-based violence'” (p. 106).

\subsubsection{Fear of non-supportive and protective responses to disclosure especially from mothers}

Barriers to disclosure for all victims are evidently steep, and fundamentally reflect deep societal shame associated with CSA (Kenny \& McEachern, 2000). Thus, it is greatly significant when a victim musters the courage to tolerate the associated stigma and disclose their abuse. This in turn points a spotlight on who they disclose to and their responses. According to Alaggia (2001), protective and supportive (maternal) responses include three key components: (a) believing the child's account of sexual abuse, (b) implementing effective actions to protect the child from further victimisation, and (c) providing positive emotional support.

\subsubsection{Parents}

Unfortunately, the literature indicates that these protective and supportive responses do not always occur from parents, for a number of reasons and in a number of ways. One reason is to avoid disruption to the family (Kenny \& McEachern, 2000; Yiming \& Fung, 2003; Lam, 2014). This issue is not exclusive to families from ethnic minority communities; Taylor and Norma (2013) report that "fear of the family being torn apart by the disclosure” (p. 118) also occurs in the Anglo Australian community. 
Another reason for non-supportive responses from ethnic minority parents is that they may be "influenced by adverse police experiences in their former homeland and (so) anticipate similarly poor responses from the Australian police” (Taylor \& Putt, 2007, p. 5). For example, Lewis (2012) says, “police in PNG are known to sexually harass and rape those reporting sexual assault, which reduces the willingness of victims and families to report” (p. 274). Fattah and Kabir (2013) also say that parents (in Bangladesh) who are aware of the abuse of their children may not disclose it to authorities because of "lack of trust in the police and legal system, fear of influential perpetrators, and unwillingness to make the incident public by taking it to the court” (p. 907).

Parents from ethnic minority communities may also not disclose the abuse to statutory authorities for fear of having their child removed (Gilligan \& Akhtar, 2005; Lewig, Arney, Salveron, \& Barredo, 2010; Yiming \& Fung, 2003). As Futa et al. (2001) say, "there is shame and loss of face when it is disclosed that a child was sexually abused. If a child is placed in an outside agency, the shame continues in the community because the family is (also) no longer intact” (p. 196).

\subsubsection{Mothers}

The literature also suggests that of all confidants, the mother's response appears most critical. As Kenny and McEachern (2000) write, “maternal support following disclosure has been identified as a mediating factor in the child's adjustment to the abuse, with those children receiving the most support faring the best emotionally after" (p. 911). However, there are many reasons why a mother from an ethnic minority community may not respond supportively and protectively. Some of these factors are non-cultural, while others are cultural in nature.

Non-cultural factors include the presence of other family issues such as parental substance abuse, mental illhealth, and/or single parenting (Mathews, Abrahams, \& Jewkes, 2013); emotional distress in response to the disclosure (Mathews et al., 2013); a possible past history of sexual abuse herself which may never have been disclosed before (Mathews et al., 2013); and the overarching dominance of an intrafamilial perpetrator (Taylor \& Norma, 2013). Cultural factors such as religion may also play a role. For example, Alaggia (2001) found that minority mothers in Canada "who believed they could support both the partner-perpetrator and the child victim maintained strong beliefs about forgiveness, sacrifice, and redemption; (viewing) forgiving as a 'good Christian act'” (p. 49). However, the most pertinent cultural reason for why an ethnic minority mother may not support her child's disclosure seems to be the need to save the family's 'face'. As Yu (1990) puts it, “concern for what others would say creates unbearable pressure, and fear of being criticised and ridiculed by others has a controlling effect on behavior” (cited in Chan et al., 2011, p. 169). 
The literature indicates that mothers from collectivist cultures face the very real and damaging risk of being cut off from their family and community should the abuse become public. Alaggia (2001) reports that minority mothers in Canada "had enormous difficulties leaving their abusive partners under any circumstances, including intra-familial child sexual abuse, because their ethnic community did not accept separation or divorce” (p. 50). Moreover, community belonging is critical for ethnic minorities in countries like Australia that have a history of judging, shaming, stereotyping, and excluding its non-mainstream constituency (Nelson, Dunn, \& Paradies, 2011). Thus, an ousting from one’s community is more than just rejection from the collectivist kinship clan, and can lead to intense social isolation for ethnic minority mothers and children. As such, the consequences of social exclusion and isolation can substantially increase non-supportive and protective maternal responses, and instead mothers may be driven to "keep the family together at all costs” (Alaggia, 2001, p. 54).

Indeed, Alaggia (2001) found that “(minority) mothers want to focus on strategies for keeping their children safe in the context of family cohesion, (but) service providers focus instead on helping them make decisions that would result in the long-term safety and mental health of the child, (so) their work is at cross-purposes” (p. 54). Thus, mothers from collectivist cultures appear to have a different construal and understanding of a 'supportive and safe response'. Importantly, Alaggia (2001) says, “this indefensible situation that (minority) women are caught in should be of particular concern for helping professionals. When mothers are put in the position of having to choose between their children and husbands (including extended family, ethnic and spiritual community), they continue to be oppressed by entrenched patriarchal structures” (p. 55).

Thus, there is an important call for workers in service organisations to be ready and equipped to address the complexity of working with victims/survivors of CSA from ethnic minority communities and their families. This is because "the (mainstream) practitioner may confront challenging considerations as the young (minority) woman de-prioritises her own need for safety, instead choosing loyalty towards family and desire for credibility, acceptance, and ongoing links within her own community” (Dawson, 2008, cited in Allimant \& Ostapiej-

Piatkowski, 2011, p. 4). Implications for practice are discussed in more detail under RQ 2.

\subsubsection{Mother-blaming discourse}

It is also critical to remember that the non-offending mother is not the perpetrator of the crime (McGuffey, 2005). Thus, rage at a non-protective parent (Capri, 2013), especially mother, might make sense from the child victim who is at risk of further abuse or secondary traumatisation from non-supportive and protective responses, 
however those working with the child and their family in a therapeutic and policy setting must be mindful not to engage in 'mother-blaming' discourse (Chien, 2008).

McGuffey (2005) says “a central premise of the mother-blaming literature is the iconography of the ideal mother (who is) ever-present, intensely available to her children, and eternally selfless. Mother-blaming perspectives downplay the uneven power relationships (between) men and women ... and centralise mothers as the cause of family problems and misfortunes ... (which is why) previous research largely excludes the voices of non-offending fathers” (p. 623-624). Positively, AlMadani et al. (2012) reported that in a sample of 87 cases examined in Saudi Arabia, the father reported the assault in 47\% of cases. However, in Zimbabwe, Birdthistle, Floyd, Mwanasa, Nyagadz, Gwiza, and Glynn (2011) report that in a quantitative review of 1,194 cases, fewer than $7 \%$ were brought by their father. More research is required to explain such cross-cultural differences between various ethnic minority groups. Overall, however, discourse that perpetuates gender inequalities should not be used when assisting a mother-child dyad in the clinical setting.

Collings (2007) also says that "nonsupportive reactions of professionals have been largely ignored” (p. 768). He found that non-supportive reactions to initial disclosure in South Africa (ignoring, punishing, or silencing the child), were roughly equal in the non-offending guardian ( $n=96 / 394 ; 24.4 \%)$ and a professional $(n=44 / 171$; 25.7\%). He says, "the fact that one in four helping professionals reacted to disclosure in a nonsupportive manner is of particular concern, suggesting the need for educational efforts directed at (all) those to whom abused children and their families turn for professional support and intervention” (p. 768-769).

\subsubsection{Summary}

Overall, the results suggest that non-supportive and protective maternal responses to disclosure are heightened in ethnic minority communities. Studies in the US, for example, have shown that mothers were significantly more likely to reject their child's information about sexual abuse if they were Asian-American and Hispanic compared to black and white families (Kenny \& McEachern, 2000). Rao, DiClemente, and Ponton (1992) also found that Asian American primary caretakers (such as mothers) were half as likely to report abuse to authorities as caretakers of other ethnic groups, more likely to disbelieve (23.4\%) the report of abuse than European American (6.7\%), African American (10.2\%), and Hispanic American (11.3\%) caretakers, and less likely than caretakers of other ethnic groups to complete the evaluation and treatment with the victim. 
Interestingly, studies have also shown that black mothers in the US have more supportive responses than white mothers (Kenny \& McEachern, 2000). This is consistent with the findings of Taylor and Norma (2013), who report that Anglo Australian victims/survivors in their sample "encountered disbelief and outright rejection by their mothers and other family members” (p. 117). Overall, more research is required into why black and white (US) mothers differ, as learnings there may have transferable bearings for both the mainstream and ethnic minorities in other Western countries like Australia.

Unfortunately, the effect of non-supportive and protective responses from a victim's mother results in "nonwhite victims faring worse after the abuse” (Kenny \& McEachern, 2000, p. 912), including worse post-traumatic stress disorder (Lam, 2015). This finding highlights that “psychosocial experiences of abuse, such as survivor responses and support provider reactions, differ according to unique meanings conferred by specific sociocultural contexts” (Ullman \& Filipas, 2005, p. 69-70). It goes against the idea that "there are more similarities than differences between ethnic groups in women's experiences following sexual abuse; that reactions are generally universal (and) transcend culture (and) racial-ethnic factors” (Kenny \& McEachern, 2000, p. 912-913).

\subsection{RQ 2: How can service organisations encourage disclosure of CSA in ethnic minority communities?}

Non-supportive and protective responses to disclosure, especially from a child victim's mother, can be detrimental to their wellbeing. Given the pressure to protect the family name in collectivist cultures, it may be useful to suggest initial disclosure of abuse to people outside of the family, such as service providers in local organisations, school counsellors, prevention program deliverers, teachers, nurses, and GPs. As these nonfamily confidants do not have a competing demand to keep the family together, it is asserted they may be more likely to respond with supportive and protective responses.

Importantly, non-family confidants need to be those with power and capacity to offer supportive and protective responses. For example, Lepore and Smyth (2002) say, "the simple act of disclosing a past traumatic experience to others could exert a positive effect on subsequent health and wellbeing” (cited in Lam, 2015, p. 734), but Fontes and Plummer (2010) point out that "children who disclose to their pets or other children, for example, may experience some catharsis but are not likely to obtain meaningful protection” (p. 494). 
It is suggested here that messages about approaching non-family confidants first could be delivered in culturally tailored school-based prevention programs, so that they are widely disseminated to children within programs that have considered culturally-relevant factors such as the importance of family reputation (see Sawrikar \& Katz, 2017a for detailed information on culturally tailored school-based CSA prevention programs for ethnic minority children). However, professional non-family confidants are mandatory reporters in Australia, and so would not be able to work with the child until they also disclosed to their parents/carers. Thus, victims who are encouraged to seek initial help from sources external to the family should also be fully informed that professionals are legally required to breach confidentiality. Once the child has also disclosed to their family later, however, the professional could work with the whole family too. Specifically, they can help educate mothers about the importance of supportive responses, especially believing the child's disclosure. Schaefer and colleagues (2012), for example, found that “if survivors are believed and measures are taken to reduce feelings of guilt, it is possible to reduce degree of psychological impairment” (cited in Chien, 2013, p. 258). In-depth examination of the relationship between CSA and mental ill-health has been reported elsewhere (see Sawrikar \& Katz, 2017b).

Education about the importance of at least believing the child's disclosure is also seen to be a culturally appropriate suggestion because it acknowledges the importance of family cohesion in collectivist cultures and its protective role (Lesmana et al., 2015; Singh \& McKleroy, 2011; Sulimani-Aidan \& Benbenishty, 2013). As Shalhoub-Kevorkian (2000) puts it, “winning the support and understanding of significant individuals dear to the victim lifts (them) from the suffocating state of isolation caused by social exclusion ... (Thus), the meaningfulness of support (may not lie) in society's perceptions of what should be done for abused (children in collectivist societies) but rather in the victim’s outlook” (p. 630-631).

Finally, professionals could explore the victim’s acculturation to identify the extent to which cultural barriers regarding the preservation of family cohesion and name are acting in their specific case; that is, acculturation may be a predictor or facilitator of disclosure. In the context of CSA, the less individuals endorse traditional collectivist cultural norms which highly value 'family face', the more likely they are to disclose (Alaggia, 2001; Foynes et al., 2014; Kenny \& McEachern, 2000). Indeed, “Katerndahl, Burge, Kellogg, and Parra (2005) found more of a correlation between acculturation level and reporting of child sexual abuse than with ethnicity itself and reporting” (cited in Fontes \& Plummer, 2010, p. 495). Importantly, acculturation may facilitate disclosure, 
but it can only be retrospectively identified as a predictor once disclosure has occurred. Thus, its facilitating role may only be explored later, as part of discussions in the clinical context.

\section{$4 \quad$ Discussion}

\subsection{Summary of key findings, future research, and significance of review}

Thematic analysis was merged in the 'Results' section, and so has not been separately described here. However across all findings, one key 'take home message' is that there are many barriers to disclosure for ethnic minority victims/survivors. These include universal (or non-cultural) barriers, as well as cultural barriers relating to preserving the family name, the overt lower social power of children, social norms regarding emotional suppression, fatalistic and/or religious beliefs, fear of reprisal (most especially social exclusion and sometimes also death), and fear of non-supportive and protective responses to disclosure especially from mothers. These cultural barriers are not exclusive to ethnic minorities, but do appear to be more intense for them. They also have the added racist barrier of fear of stigmatising their entire community. While these barriers have been identified from the reviewed literature, much more research in the area is required. Thus, we only claim here that barriers from the current body of literature have been exhausted, but not that all barriers for this group have been identified.

To help mobilise the role of service organisations in addressing these barriers, it is suggested that victims could be encouraged to disclose initially to professionals. The effectiveness of this suggestion does require substantial and rigorous evaluative research given that evidence of non-supportive responses to initial disclosure among professionals has been previously identified (Collings, 2007), however such an endeavour would at least help progress the field with empirical data as well as evidence of the importance of service worker training. This is especially the case in Australia where research is essentially absent; threatening the development of best practice guidelines that are systematically implemented as part of standard practice and knowledge for all client ethnic minority children and families.

Overall, this review is significant because in conducting such a wide and comprehensive scoping of the relevant literature it begins to address the current gap in national knowledge, and shows that many barriers to disclosure among ethnic minorities are shared with the mainstream (even if not to the same extent). It also shows that racism is not shared, and since it is a critical and immense barrier the needs of ethnic minorities must be met 
with utmost sensitivity and vigilance on racist thinking and practice. That is, the review allows cross-cultural similarities and differences to be better mapped.

Many of the themes here have been identified from literature based in the US and UK, where research on ethnic minorities is substantially better developed than in Australia. Thus, for international readers it may appear that this review offers limited new insights. In Australia, where such conversation has not yet begun, describing the full array of relevant variables is highly significant. However, beyond just 'taking stock' of the field by describing all barriers to disclosure among ethnic minorities, this narrative review has critically synthesised them in ways that do offer new understandings of the current body of work. Specifically, it 'operationalises' culture into individualism and collectivism, thereby not being defeated by the difficulty associated with defining 'culture' and the net effect of failing to progress the field meaningfully. It also makes these concepts 'front and centre' in the way culture, at least broadly, is used to make sense of the needs and experiences of ethnic minority CSA victims/survivors. Much of the reviewed literature speaks to the issues of collectivism, or family importance, but this paper uses it as the theoretical framework to centralise its critical and fundamental role. Using this framework to synthesise the current knowledge base is a contribution to both Australian and international audiences.

\subsection{Conclusion}

The literature shows that family reputation is a central factor in understanding the many barriers to disclosure among victims/survivors of CSA from ethnic minority communities. It is critical that all service providers be aware of and sensitive to this when providing services to children and families from ethnic minority communities, else they risk providing services that are not culturally appropriate. In this respect, service provider training appears critical, so that such cultural knowledge is not simply left to be discovered ad hoc in the clinical setting. Perhaps even more critically, such training could also be used to educate service providers about the unique barrier to disclosure of racism, so that it is not at risk of being overlooked or minimised. 


\section{References}

Ajzenstadt, M., \& Cavaglion, G. (2005). Stories about child sexual abuse: Textual analysis of instruction manuals in Israel. Qualitative Sociology, 28(3), 255-274.

Alaggia, R. (2001). Cultural and religious influences in maternal response to intrafamilial child sexual abuse: Charting new territory for research and treatment. Journal of Child Sexual Abuse, 10(2), 41-60.

Allimant, A., \& Ostapiej-Piatkowski, B., (2011). Studies, (2011). Supporting women from CALD backgrounds who are victims/survivors of sexual violence: challenges and opportunities for practitioners. Australian Centre for the Study of Sexual Assault (ACSSA) Wrap, No. 9, 1-16, Melbourne: Australian Institute of Family Studies.

AlMadani, O., Bamousa, M., Alsaif, D., Kharoshah, M. A. A., \& Alsowayigh, K. (2012). Child physical and sexual abuse in Dammam, Saudi Arabia: A descriptive case-series analysis study. Egyptian Journal of Forensic Sciences, 2(1), 33-37.

Anderson, P. \& Wild, R. (2007). Ampe Akelyernemane Meke Mekarle (Little Children Are Sacred): Report of the Board of Inquiry into the Protection of Aboriginal Children from Sexual Abuse 2007. Department of the Chief Minister, Northern Territory Government.

Armstrong, A. (1998). Consent and compensation: The sexual abuse of girls in Zimbabwe. In W. Ncube (Ed.), Law, culture, tradition and children's rights in Eastern and Southern Africa (pp. 129-149). Ashgate Dartmouth: Aldershot.

Australian Bureau of Statistics (ABS, 2016). Catalogue No. 2071.0: Census of Population and Housing: Reflecting Australia - Stories from the Census, 2016. Canberra: Author.

Australian Bureau of Statistics (ABS, 2012-2013). Catalogue No. 2071.0: Cultural diversity in Australia Reflecting a Nation: Stories from the 2011 Census. Canberra: Author.

Australian Bureau of Statistics (ABS, 2012). Catalogue No. 1301.0: Year Book of Australia, 2012. Canberra: Author.

Back, S. E., Jackson, J. L., Fitzgerald, M., Shaffer, A., Salstrom, S., \& Osman, M. M. (2003). Child sexual and physical abuse among college students in Singapore and the United States. Child Abuse and Neglect, 27(11), 1259-1275. 
Baker, C. K., Gleason, K., Naai, R., Mitchell, J., \& Trecker, C. (2013). Increasing knowledge of sexual abuse: A study with elementary school children in Hawai’i. Research on Social Work Practice, 23(2), 167-178.

Barker-Collo, S., Read, J., \& Cowie, S. (2012). Coping strategies in female survivors of childhood sexual abuse from two Canadian and two New Zealand cultural groups. Journal of Trauma and Dissociation, 13(4), $435-447$.

Bernard, C. (2002). Parental maltreatment of black children in the context of societal racism. Child and Family Social Work, 7(4), 239-51.

Berry, J. W. (1980). Acculturation as varieties of adaptation. In A. M. Padilla (Ed.), Acculturation: Theory, models, and some new findings. Boulder, CO: Westview.

Birdthistle, I. J., Floyd, S., Mwanasa, S., Nyagadz, A., Gwiza, E., \& Glynn, J. R. (2011). Child sexual abuse and links to HIV and orphanhood in urban Zimbabwe. Journal of Epidemiology and Community Health, 65(12), 1075-1082.

Boakye, K. E. (2009). Culture and nondisclosure of child sexual abuse in Ghana: A theoretical and empirical exploration. Law and Social Inquiry, 34(4), 951-979.

Bond, M. H. (2002). Reclaiming the individual from Hofstede’s ecological analysis-A 20-year odyssey: Comment on Oyserman et al. (2002). Psychological Bulletin, 128, 73-77.

Bromfield, L. \& Arney, F. (2008) Developing a road map for research: Identifying priorities for a national child protection research agenda: Issues paper. Australian Institute of Family Studies, No 28.

Burke, S. \& Paxman, M. (2008). Children and young people from non-English speaking backgrounds in Out of Home Care in NSW. Sydney: NSW Department of Community Services.

Burton, L., Westen, D., \& Kowalski, R. (2015). Psychology: Australian and New Zealand edition (4 ${ }^{\text {th }}$ ed.). Milton, Australia: John Wiley and Sons.

Capri, C. (2013). Madness and defence: Interventions with sexually abused children in a low-income South African community. European Journal of Psychotherapy and Counselling, 15(1), 32-52.

Cashmore, J., Higgins, D. J., Bromfield, L., \& Scott, D. A. (2006). Recent Australian child protection and out of home care research: What's been done and what needs to be done? Children Australia, 31(2), 4-11. 
Chan, Y. C., Lam, G. L. T., \& Shae, W. C. (2011). Children's views on child abuse and neglect: Findings from an exploratory study with Chinese children in Hong Kong. Child Abuse and Neglect, 35(3), 162-172.

Chen, J. Q., \& Chen, D. G. (2005). Awareness of child sexual abuse prevention education among parents of Grade 3 elementary school pupils in Fuxin City, China. Health Education Research, 20(5), 540-547.

Chen, J., Dunne, M. P., \& Han, P. (2004). Child sexual abuse in China: A study of adolescents in four provinces. Child Abuse and Neglect, 28(11), 1171-1186.

Chien, M. H. (2013). Identifying key components of an internet information system for Chinese survivors of childhood sexual abuse. Journal of Ethnic and Cultural Diversity in Social Work, 22(3-4), 256-270.

Chien, M. H. (2008). The current relationships of Taiwanese women with a history of childhood sexual abuse to their non-offending mothers. Journal of Social Service Research, 34(4), 29-39.

Choi, K. S., Choo, K., Choi, J., \& Woo, Y. (2015). Understanding the dynamics of the victim-perpetrator relationship in child sexual abuse: An examination of the child sex abuse victimization data in South Korea. Asian Journal of Criminology, 10(1), 79-97.

Collings, S. J., Griffiths, S., \& Kumalo, M. (2005). Patterns of disclosure in child sexual abuse. South African Journal of Psychology, 35(2), 270-285.

Collings, S. J. (2007). Nonsupportive disclosure in child sexual abuse: Confidants’ characteristics and reactions. Psychological Reports, $100(3 \mathrm{I}), 768-770$.

Corrigan, P. (2004). How stigma interferes with mental health care. American Psychologist, 59(7), 614-625.

Dawson, J. (2008). What about the children? The voices of culturally and linguistically diverse children affected by family violence. Melbourne: Immigrant Women’s Domestic Violence Service.

Elbedour, S., Abu-Bader, S., Onwuegbuzie, A. J., Abu-Rabia, A., \& El-Aassam, S. (2006). The scope of sexual, physical, and psychological abuse in a Bedouin-Arab community of female adolescents: The interplay of racism, urbanization, polygamy, family honor, and the social marginalization of women. Child Abuse and Neglect, 30(3), 215-229.

Fanslow, J. L., Robinson, E. M., Crengle, S., \& Perese, L. (2007). Prevalence of child sexual abuse reported by a cross-sectional sample of New Zealand women. Child Abuse and Neglect, 31(9), 935-945. 
Fattah, K. N., \& Kabir, Z. N. (2013). No place is safe: Sexual abuse of children in rural Bangladesh. Journal of Child Sexual Abuse, 22(8), 901-914.

Finkelhor, D. (1994). Current information on the scope and nature of child sexual abuse. Future Child, 4, 31-53.

Fontes, L. A., \& Plummer, C. (2010). Cultural issues in disclosures of child sexual abuse. Journal of Child Sexual Abuse, 19(5), 491-518.

Fontes, L. A. (2005). Child abuse and culture: Working with diverse families. New York: Guilford Press.

Fontes, L. (1997). Evaluating the cultural sensitivity of child abuse research: Sampling issues. American Professional Society on the Abuse of Children Advisor, 10, 8-10.

Fontes, L. (1993). Considering culture and oppression. Journal of Feminist Family Therapy, 5(1), $25-54$.

Foynes, M. M., Platt, M., Hall, G. C. N., \& Freyd, J. J. (2014). The impact of Asian values and victimperpetrator closeness on the disclosure of emotional, physical, and sexual abuse. Psychological Trauma: Theory, Research, Practice, and Policy, 6(2), 134-141.

Futa, K. T., Hsu, E., \& Hansen, D. J. (2001). Child sexual abuse in Asian American families: An examination of cultural factors that influence prevalence, identification, and treatment. Clinical Psychology: Science and Practice, 8(2), 189-209.

Gilligan, P., \& Akhtar, S. (2005). Child sexual abuse among Asian communities: Developing materials to raise awareness in Bradford. Practice (UK), 17(4), 267-284.

Haboush, K. L., \& Alyan, H. (2013). “Who can you tell?” Features of Arab Culture that influence conceptualization and treatment of childhood sexual abuse. Journal of Child Sexual Abuse, 22(5), 499-518.

Haj-Yahia, M. M., \& Tamish, S. (2001). The rates of child sexual abuse and its psychological consequences as revealed by a study among Palestinian university students. Child Abuse and Neglect, 25(10), 1303-1327.

Henderson, A. (2007). Islam and Australia: The next phase. Sydney Institute Quarterly, 30, 9-13.

Hofstede (2001): http://www.clearlycultural.com/geert-hofstede-cultural-dimensions/individualism/

Hofstede, G. H. (1980). Culture’s consequences: international differences in work-related values. Beverly Hills, Calif: Sage Publications. 
Huisman, K., Martinez, J., \& Wilson, C. (2005). Training police officers on domestic violence and racism. Violence Against Women, 11(6), 792-821.

Human Rights and Equal Opportunities Commission (HREOC) (1997). Bringing them home: Report of the national inquiry into the separation of Aboriginal and Torres Strait Islander children from their families. Canberra, Human Rights and Equal Opportunities Commission.

Jackson, V. (2010). Racism and child protection: A\&C Black.

Ji, K., Finkelhor, D., \& Dunne, M. (2013). Child sexual abuse in China: A meta-analysis of 27 studies. Child Abuse and Neglect, 37(9), 613-622.

Jiwani, Y. (2005). Walking a tightrope: The many faces of violence in the lives of racialized immigrant girls and young women. Violence Against Women, 11(7), 846-875.

Johns, G. (2008). The Northern Territory Intervention in Aboriginal affairs: Wicked problem or wicked policy? Agenda: A Journal of Policy Analysis and Reform, 15(2), 65-84.

Karthiga, R. K. J., \& Ravikumar, R. (2014). Child sexual abuse in Madurai, India: A literary review and empirical study. Journal of Child Sexual Abuse, 23(6), 727-744.

Kaseke, S. (2010). ‘Standing together on a riverbank’: Group conversations about sexual abuse in Zimbabwe. International Journal of Narrative Therapy and Community Work, 2010(4), 42-44.

Katerndahl, D., Burge, S., Kellogg, N., \& Parra, J. (2005). Differences in childhood sexual abuse experience between adult Hispanic and Anglo women in a primary care setting. Journal of Child Sexual Abuse, 14(2), 8595.

Kenny, M. C., \& McEachern, A. G. (2000). Racial, ethnic, and cultural factors of childhood sexual abuse: A selected review of the literature. Clinical Psychology Review, 20(7), 905-922.

Lalor, K. (2004). Child sexual abuse in sub-Saharan Africa: A literature review. Child Abuse and Neglect, 28(4), 439-460.

Lam, K. Y. I. (2015). Disclosure and psychological well-Being of sexually abused adolescents in Hong Kong. Journal of Child Sexual Abuse, 24(7), 731. 
Lam, K. Y. I. (2014). Factors associated with adolescents’ disclosure of sexual abuse experiences in Hong Kong. Journal of Child Sexual Abuse, 23(7), 768-791.

Laungani, P. (2003). Sexual abuse in an Asian family. Counselling Psychology Quarterly, 16(4), 385-401.

Lepore, S. J., \& Smyth, J. M. (2002). The writing cure. Washington DC: APA Press.

Lesmana, C. B. J., Suryani, L. K., \& Tiliopoulos, N. (2015). Cultural considerations in the treatment of mental illness among sexually abused children and adolescents: The case of Bali, Indonesia. Vol. 2015. New Directions for Child and Adolescent Development (pp. 109-116).

Lewig, K., Arney, F., Salveron, M., \& Barredo, M. (2010). Parenting in a new culture: Working with refugee families (pp. 157-186). Cambridge: Cambridge University Press.

Lewis, I. R. (2012). At risk: The relationship between experiences of child sexual abuse and Women’s HIV status in Papua New Guinea. Journal of Child Sexual Abuse, 21(3), 273-294.

Li, N., Ahmed, S., \& Zabin, L. S. (2012). Association between childhood sexual abuse and adverse psychological outcomes among youth in Taipei. Journal of Adolescent Health, 50(3, Suppl), S45-S51.

Lin, D., Xiaoming, L., Fang, X., \& Lin, X. (2011). Childhood sexual abuse and sexual risks among young ruralto-urban migrant women in Beijing, China. AIDS Care, 23(supp 1), 113-119.

Luo, T. Y. (2000). “Marrying my rapist?!”: The cultural trauma among Chinese rape survivors. Gender and Society, 14(4), 581-597.

Ma, E. Y., \& Li, F. W. (2014). Developmental trauma and its correlates: A study of Chinese children with repeated familial physical and sexual abuse in Hong Kong. Journal of Traumatic Stress, 27(4), 454-460.

Macoun, A. (2011). Aboriginality and the Northern Territory Intervention. Australian Journal of Political Science, 46(3), 519-534.Mathews, B., Walsh, K., Dunne, M., Katz, I., Arney, F., Higgins, D.,... \& Bates, S. (2016). Scoping study for research into the prevalence of child abuse in Australia: Report to the Royal Commission into Institutional Responses to Child Sexual Abuse. Sydney: Social Policy Research Centre, UNSW Australia in partnership with Australian Institute of Family Studies, Queensland University of Technology and the Australian Centre for Child Protection (University of South Australia). 
Mathews, S., Abrahams, N., \& Jewkes, R. (2013). Exploring mental health adjustment of children post sexual assault in South Africa. Journal of Child Sexual Abuse, 22(6), 639-657.

McGuffey, C. (2005). Engendering trauma: Race, class, and gender reaffirmation after child sexual abuse. Gender and Society, 19(5), 621-643.

Menjivar, C., \& Salcido, O. (2002). Immigrant women and domestic violence: Common experiences in different countries. Gender and Society, 16, 898-920.

Mildred, J., \& Plummer, C. A. (2009). Responding to child sexual abuse in the United States and Kenya: Child protection and children's rights. Children and Youth Services Review, 31(6), 601-608.

Moher, D., Liberati, A., Tetzlaff, J., \& Altman, D. G., \& The PRISMA Group. (2009). Preferred Reporting Items for Systematic Reviews and Meta-Analyses: The PRISMA Statement. PLoS Med, 6(7), e1000097.

Nelson, J. K., Dunn, K. M., \& Paradies, Y. (2011). Australian racism and anti-racism: Links to morbidity and belonging. In F. Mansouri \& M. Lobo (Eds.), Migration, Citizenship and Intercultural Relations: Looking Through the Lens of Social Inclusion. Surrey, UK: Ashgate Publishing Ltd.

Neustein, A., \& Lesher, M. (2008). A single-case study of Rabbinic sexual abuse in the orthodox Jewish community. Journal of Child Sexual Abuse, 17(3-4), 270-289.

O’Hagan. (1999). Culture, cultural identity, and cultural sensitivity in child and family social work. Child and Family Social Work, 4(4), 269-281.

Owusu-Bempah, K., \& Howitt, D. (2000). Psychology beyond Western perspectives: London: Wiley-Blackwell. Pereda, N., Guilera, G., Forns, M., \& Gomez-Benito, J. (2009). The international epidemiology of child sexual abuse: A continuation of Finkelhor (1994). Child Abuse and Neglect, 33(6), 331-342.

Rao, K., DiClemente, R. J., \& Ponton, L. E. (1992). Child sexual abuse of Asians compared with other populations. Journal of the American Academy of Child and Adolescent Psychiatry, 31, 880-886.

Reavey, P., Ahmed, B., \& Majumdar, A. (2006). 'How can we help when she won’t tell us what's wrong?' Professionals working with South Asian women who have experienced sexual abuse. Journal of Community and Applied Social Psychology, 16(3), 171-188. 
Salter, M. (2014). Multi-perpetrator domestic violence. Trauma, Violence, and Abuse: A Review Journal, 15(2), $102-112$.

Sawrikar, P. (2017). Working effectively with ethnic minorities and across cultures in Western child protection systems. UK: Routledge.

Sawrikar, P. (2011). Culturally appropriate service delivery for Culturally and Linguistically Diverse (CALD) families in the child protection system: Interim Report 2 - Case File Review. Report for the NSW Department of Community Services.

Sawrikar, P. (2008). To cause or not to cause a scene? Exploring the relationship between culture, emotional suppression and mental health among adolescents in Australia. Doctoral dissertation. VDM Verlag: Saarbrucken, Germany.

Sawrikar, P. \& Katz, I. (2017a). Preventing child sexual abuse (CSA) in ethnic minority communities: A literature review and suggestions for practice in Australia. Children and Youth Services Review, under review.

Sawrikar, P. \& Katz, I. (2017b). The treatment needs of victims/survivors of child sexual abuse (CSA) from ethnic minority communities: A literature review and suggestions for practice. Children and Youth Services Review, 79, 166-179.

Sawrikar, P. \& Katz, I. (2010). “Only White people can be racist”: What does power have to do with prejudice? Cosmopolitan Civil Societies, 2(1), 80-99.

Sawrikar, P. \& Katz, I. (2009). How useful is the term “Culturally and Linguistically Diverse (CALD)" in the Australian social policy discourse? Refereed Conference Paper, Australian Social Policy Conference (ASPC) 2009.

Sawrikar, P. \& Katz, I. (2008). Enhancing family and relationship service accessibility and delivery to culturally and linguistically diverse (CALD) families in Australia, Issues paper prepared for the Australian Family Relationships Clearinghouse (AFRC), Issues No. 3.

Sawrikar, P., \& Hunt, C. J. (2005). The relationship between mental health, cultural identity and cultural values in non-English speaking background (NESB) Australian adolescents. Behaviour Change, 22(2), 97-113. 
Schaefer, G. A., Mundt, I. A., Ahlers, C. J., \& Bahls, C. (2012). Child sexual abuse and psychological impairment in victims: Results of an online study initiated by victims. Journal of Child Sexual Abuse, 21(3), 343-360.

Shalhoub-Kevorkian, N. (2005). Disclosure of child abuse in conflict areas. Violence Against Women, 11(10), 1263-1291.

Shalhoub-Kevorkian, N. (2000). Blocking her exclusion: A contextually sensitive model of intervention for handling female abuse. Social Service Review, 74(4), 620-634.

Sil, K. H., \& Soo, K. H. (2008). Intra-familial sexual abuse (incest) among Korean adolescents. Family Relations: 21st Century Issues and Challenges (pp. 71-86).

Singh, A. A. (2009). Helping South Asian immigrant women use resilience strategies in healing from sexual abuse: A call for a culturally relevant model. Women and Therapy, 32(4), 361-376.

Singh, A. A., \& McKleroy, V. S. (2011). “Just getting out of bed is a revolutionary act”: The resilience of transgender people of color who have survived traumatic life events. Traumatology, 17(2), 34-44.

Stoltenborgh, M., van Ijzendoorn, M. H., Euser, E. M., \& Bakermans-Kranenburg, M. J. (2011). A global perspective on child sexual abuse: Meta-analysis of prevalence around the world. Child Maltreatment, 16(2), 79-101.

Sulimani-Aidan, Y., \& Benbenishty, R. (2013). Child maltreatment reports in Israel: The intersection between community socioeconomic characteristics and ethnicity. American Journal of Orthopsychiatry, 83(1), 29-36.

Taylor, N., \& Putt, J. (2007). Adult sexual violence in Indigenous and culturally and linguistically diverse communities in Australia. Canberra: Australian Institute of Criminology.

Taylor, S., \& Norma, C. (2013). The ties that bind: Family barriers for adult women seeking to report childhood sexual assault in Australia. Women’s Studies International Forum, 37, 114-124.

Thill, C. (2009). Courageous listening, responsibility for the other and the Northern Territory Intervention. Continuum, 23(4), 537-548.

Triandis, H. C. (1990). Theoretical concepts that are applicable to the analysis of ethnocentricism. In R. W. Brislin (Ed.), Applied cross-cultural psychology. New York: Sage. 
Ullman, S. E., \& Filipas, H. H. (2005). Ethnicity and child sexual abuse experiences of female college students. Journal of Child Sexual Abuse, 14(3), 67-89.

Usta, J., \& Farver, J. (2010). Child sexual abuse in Lebanon during war and peace. Child: Care, Health and Development, 36(3), 361-368.

Wang, Y. W., \& Heppner, P. (2011). A qualitative study of childhood sexual abuse survivors in Taiwan:

Toward a transactional and ecological model of coping. Journal of Counseling Psychology, 58(3), 393-409.

Wilson, M. (1994). Crossing the boundary: Black women survive incest. Seattle, WA: Seal Press.

Wilson, M. (1993). Crossing the boundary. London: Virago.

Yiming, C., \& Fung, D. (2003). Child sexual abuse in Singapore with special reference to medico-legal implications: A review of 38 cases. Medicine, Science and the Law, 43(3), 260-266.

Yoshihama, M., \& Horrocks, J. (2010). Risk of intimate partner violence: Role of childhood sexual abuse and sexual initiation in women in Japan. Children and Youth Services Review, 32(1), 28-37.

Yu, A. B. (1990). The construct validity of social-oriented and individual-oriented achievement motivation [in Chinese]. Unpublished doctoral dissertation, Department of Psychology, National Taiwan University, Taiwan. 
Appendix A: Summary of articles obtained from PRISMA process used to answer RQs 1 and 2

\begin{tabular}{|c|c|c|c|}
\hline AUTHORS & $\begin{array}{l}\text { COUNTRY/IES STUDY } \\
\text { CONDUCTED IN }\end{array}$ & METHOD & RIGOROUS \\
\hline \multicolumn{4}{|c|}{ Includes or mostly based in Western contexts } \\
\hline 1. Alaggia (2001) & Canada (Various) & Qualitative & $\begin{array}{l}\text { Thematic saturation } \\
\text { reached }\end{array}$ \\
\hline $\begin{array}{l}\text { 2. Allimant \& Ostapiej- } \\
\text { Piatkowski (2011) }\end{array}$ & Australia (Various) & $\begin{array}{l}\text { Secondary analysis } \\
\text { (literature review) }\end{array}$ & \\
\hline 3. Back et al. (2003) & Singapore/USA & Quantitative & \\
\hline 4. Baker et al. (2013) & Hawai’i & Quantitative & \\
\hline 5. $\quad$ Barker-Collo et al. (2012) & Canada/New Zealand & Quantitative & \\
\hline 6. Fanslow et al. (2007) & New Zealand & Quantitative & $\begin{array}{l}\text { Large, representative } \\
\text { sample }(\mathrm{n}=2,855)\end{array}$ \\
\hline 7. Fontes \& Plummer (2010) & USA & $\begin{array}{l}\text { Secondary analysis } \\
\text { (literature review) }\end{array}$ & \\
\hline 8. Fontes (2005) & USA & $\begin{array}{l}\text { Secondary analysis } \\
\text { (literature review) }\end{array}$ & \\
\hline 9. Foynes et al. (2014) & USA (Asians) & Quantitative & Large sample $(n=266)$ \\
\hline 10. Futa et al. (2001) & USA (East Asians) & $\begin{array}{l}\text { Secondary analysis } \\
\text { (literature review) }\end{array}$ & \\
\hline 11. Gilligan \& Akhtar (2005) & UK (South Asians) & Qualitative & \\
\hline 12. Haboush \& Alyan (2013) & USA (Arabs) & $\begin{array}{l}\text { Secondary analysis } \\
\text { (literature review) }\end{array}$ & \\
\hline 13. Henderson (2007) & Australia (Muslims) & $\begin{array}{l}\text { Secondary analysis } \\
\text { (Commentary) }\end{array}$ & \\
\hline $\begin{array}{l}\text { 14. Kenny \& McEachern } \\
\text { (2000) }\end{array}$ & USA (Various) & $\begin{array}{l}\text { Secondary analysis } \\
\text { (literature review) }\end{array}$ & \\
\hline
\end{tabular}




\begin{tabular}{|c|c|c|c|}
\hline 15. Laungani (2003) & UK (South Asian) & Qualitative & \\
\hline 16. McGuffey (2005) & USA (Various) & Qualitative & Large sample $(n=60)$ \\
\hline $\begin{array}{l}\text { 17. Mildred \& Plummer } \\
\text { (2009) }\end{array}$ & USA/Kenya & $\begin{array}{l}\text { Secondary analysis } \\
\text { (literature review) }\end{array}$ & \\
\hline 18. Neustein \& Lesher (2008) & USA & Qualitative & \\
\hline 19. Pereda et al. (2009) & Spain & $\begin{array}{l}\text { Quantitative (meta- } \\
\text { analysis) }\end{array}$ & \\
\hline 20. Reavey et al. (2006) & UK (South Asians) & Qualitative & \\
\hline 21. Salter (2014) & Australia (Muslims) & $\begin{array}{l}\text { Secondary analysis } \\
\text { (literature review) }\end{array}$ & \\
\hline 22. Singh (2009) & USA (South Asians) & $\begin{array}{l}\text { Secondary analysis } \\
\text { (literature review) }\end{array}$ & \\
\hline 23. Singh \& McKleroy (2011) & $\begin{array}{l}\text { USA (Transgender people } \\
\text { of colour) }\end{array}$ & Qualitative & \\
\hline 24. Stoltenborgh et al. (2011) & Netherlands & Quantitative & Meta-analysis \\
\hline 25. Taylor \& Norma (2013) & Australia (Various) & Qualitative & \\
\hline $\begin{array}{l}\text { 26. Tishelman \& Geffner } \\
\text { (2010) }\end{array}$ & USA (Various) & $\begin{array}{l}\text { Secondary analysis } \\
\text { (editorial } \\
\text { introduction) }\end{array}$ & \\
\hline 27. Ullman \& Filipas (2005) & USA (Various) & Quantitative & Large sample $(n=461)$ \\
\hline 28. Wang \& Heppner (2011) & USA (Taiwanese) & Qualitative & Confirmability checked \\
\hline \multicolumn{4}{|c|}{ Mostly based in non-Western contexts } \\
\hline $\begin{array}{l}\text { 29. Ajzenstadt \& Cavaglion } \\
\text { (2005) }\end{array}$ & Israel & Qualitative & \\
\hline 30. AlMadani et al. (2012) & Saudi Arabia & Quantitative & \\
\hline
\end{tabular}




\begin{tabular}{|c|c|c|c|}
\hline 31. Birdthistle et al (2011) & Zimbabwe & Quantitative & Large sample $(\mathrm{n}=1,194)$ \\
\hline 32. Boakye (2009) & Ghana & Quantitative & \\
\hline 33. Capri (2013) & South Africa & Qualitative & \\
\hline 34. Chan et al. (2011) & Hong Kong & Qualitative & Large sample $(\mathrm{n}=87)$ \\
\hline 35. Chen \& Chen (2005) & China & Quantitative & Large sample $(\mathrm{n}=385)$ \\
\hline 36. Chen et al. (2004) & China & Quantitative & $\begin{array}{l}\text { Large, representative } \\
\text { sample }(\mathrm{n}=2,300)\end{array}$ \\
\hline 37. Chien (2013) & China & Quantitative & \\
\hline 38. Chien (2008) & Taiwan & Qualitative & \\
\hline 39. Choi et al. (2015) & South Korea & Quantitative & \\
\hline 40. Collings (2007) & South Africa & Quantitative & Large sample $(\mathrm{n}=856)$ \\
\hline 41. Elbedour et al. (2006) & Israel & Quantitative & \\
\hline 42. Fattah \& Kabir (2013) & Bangladesh & Quantitative & Large sample $(\mathrm{n}=713)$ \\
\hline $\begin{array}{l}\text { 43. Haj-Yahia \& Tamish } \\
\text { (2001) }\end{array}$ & Palestine & Quantitative & \\
\hline 44. Ji et al. (2013) & China & Quantitative & \\
\hline $\begin{array}{l}\text { 45. Karthiga \& Ravikumar } \\
\text { (2014) }\end{array}$ & India & Mixed method & \\
\hline 46. Kaseke (2010) & Zimbabwe & Qualitative & \\
\hline 47. Lalor (2004) & Sub-Saharan Africa & $\begin{array}{l}\text { Secondary analysis } \\
\text { (literature review) }\end{array}$ & \\
\hline 48. Lam (2015) & Hong Kong & Quantitative & \\
\hline 49. Lam (2014) & Hong Kong & Quantitative & Large sample $(\mathrm{n}=830)$ \\
\hline
\end{tabular}




\begin{tabular}{|c|c|c|c|}
\hline 50. Lesmana et al. (2015) & Indonesia & Qualitative & \\
\hline 51. Lewis (2012) & Papua New Guinea & Mixed method & \\
\hline 52. Li et al. (2012) & Taipei & Quantitative & $\begin{array}{l}\text { Large, representative } \\
\text { sample ( } \mathrm{n}=4,084)\end{array}$ \\
\hline 53. Lin et al. (2011) & China & Quantitative & Large sample $(\mathrm{n}=478)$ \\
\hline 54. Luo (2000) & Taiwan & Qualitative & \\
\hline 55. Ma \& Li (2014) & Hong Kong & Quantitative & \\
\hline 56. Mathews et al. (2013) & South Africa & Mixed method & \\
\hline $\begin{array}{l}\text { 57. Shalhoub-Kevorkian } \\
\text { (2000) }\end{array}$ & Palestine & $\begin{array}{l}\text { Secondary analysis } \\
\text { (literature review) }\end{array}$ & \\
\hline 58. Sil \& Soo (2008) & Korea & Qualitative & \\
\hline $\begin{array}{l}\text { 59. Sulimani-Aidan \& } \\
\text { Benbenishty (2013) }\end{array}$ & Israel & Quantitative & \\
\hline 60. Usta \& Farver (2010) & Lebanon & Quantitative & Large sample $(\mathrm{n}=1,028)$ \\
\hline 61. Yiming \& Fung (2003) & Singapore & Quantitative & \\
\hline $\begin{array}{l}\text { 62. Yoshihama \& Horrocks } \\
\text { (2010) }\end{array}$ & Japan & Quantitative & Large sample $(\mathrm{n}=1,371)$ \\
\hline
\end{tabular}

